\title{
Seroprevalence of African horse sickness in selected donkey populations in Namibia
}

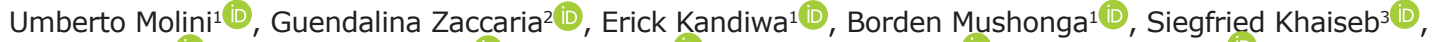

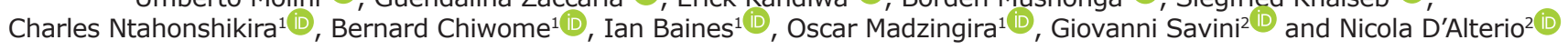 \\ 1. Department of Pathobiology, School of Veterinary Medicine, Faculty of Agriculture and Natural Resources, University \\ of Namibia, Neudamm Campus, Namibia; 2. Istituto Zooprofilattico Sperimentale dell'Abruzzo e del Molise "G. Caporale" \\ 64100 Teramo, Italy; 3. Department of Virology, Central Veterinary Laboratory, 24 Goethe Street, Windhoek, Namibia. \\ Corresponding author: Umberto Molini, e-mail: u.molini76@gmail.com \\ Co-authors: GZ: guendalina.zaccaria@gmail.com, EK: ekandiwa@unam.na, BM: bmushonga@unam.na, \\ SK: khaisebs@gmail.com,CN: cntahonshikira@unam.na,BC: bchiwome@unam.na, IB: ibaines@unam.na, \\ OM: omadzingira@unam.na, GS: g.savini@izs.it, ND: n.dalterio@izs.it \\ Received: 30-11-2019, Accepted: 20-04-2020, Published online: 31-05-2020
}

doi: www.doi.org/10.14202/vetworld.2020.1005-1009 How to cite this article: Molini U, Zaccaria G, Kandiwa E, Mushonga B, Khaiseb S, Ntahonshikira C, Chiwome B, Baines I, Madzingira O, Savini G, D'Alterio N (2020) Seroprevalence of African horse sickness in selected donkey populations in Namibia, Veterinary World, 13(5): 1005-1009.

\begin{abstract}
Background and Aim: African horse sickness (AHS) is a non-contagious viral disease of horses and other equids caused by an arbovirus belonging to the Reoviridae family and genus Orbivirus. AHS is an endemic disease that is responsible for the death of a high number of horses every year in Namibia. At present, there is no information on the prevalence and distribution of AHS virus (AHSV) serotypes in the different regions of Namibia. Therefore, this survey aimed to fill this knowledge gap by investigating the AHSV seroprevalence in Namibian donkeys.

Materials and Methods: A total of 260 blood samples (20 samples for each region) were randomly collected from donkeys aged between 3 and 5 years. Sera were screened for AHSV-specific immunoglobulin G antibodies using acommercial competitive enzyme-linked immunosorbent assay kit and samples positive to AHSV antibodies were further tested by serum neutralization (SN) assay to evaluate the AHSV serotype-specific immune response.

Results: Seroprevalence of antibodies against AHSV in Namibian donkeys was 63.5\%. The AHSV prevalence was significantly higher in the northern region $(64 \%)$ than in the southern region $(36 \%)$. A significantly $(p<0.05)$ higher number of donkeys had antibodies against AHSV-6 (37.8\%) and AHSV-9 (37.8\%). The AHSV-2, AHSV-6, and AHSV-9 prevalence were higher $(p<0.05)$ in the northern regions compared to the southern regions. None of the donkeys in this study, however, tested positive for AHSV-8.

Conclusion: Results of the current study indicate that all AHSV serotypes have either circulated previously or are circulating in Namibia except for AHSV-8. In particular, AHSV-1, -2, -3, -4, -5, -6, and -9 serotypes have circulated or are circulating in the northern region of Namibia, while AHSV-1, -4, -5, -6, -7, and -9 have infected donkeys in the south. AHSV-9 and AHSV-6 were the most prevalent serotypes detected in donkeys in this study. SN results showed that several donkeys from Kavango East, Kavango West, and Ohangwena regions had been exposed to multiple serotypes, indicating the possibility of cocirculation of several strains in Namibia.
\end{abstract}

Keywords: African horse sickness, donkeys, enzyme-linked immunosorbent assay, Namibia.

\section{Introduction}

African horse sickness (AHS) is a non-contagious viral disease of horses and other equids (mules, donkeys, hinnies, and zebras) caused by an arbovirus belonging to the Reoviridae family, genus Orbivirus, and transmitted by hematophagous Culicoides midges [1]. The virus can cause an acute or subacute fatal disease in unvaccinated horses, characterized by respiratory and/or circulatory impairments [2]. In African donkeys (Equus africanus) and zebra (Equus quagga), infection is generally asymptomatic and the

Copyright: Molini, et al. Open Access. This article is distributed under the terms of the Creative Commons Attribution 4.0 International License (http://creativecommons.org/licenses/by/4.0/), which permits unrestricted use, distribution, and reproduction in any medium, provided you give appropriate credit to the original author(s) and the source, provide a link to the Creative Commons license, and indicate if changes were made. The Creative Commons Public Domain Dedication waiver (http://creativecommons.org/ publicdomain/zero/1.0/) applies to the data made available in this article, unless otherwise stated. two species are considered to be vertebrate reservoirs of the virus [2]. To date, nine distinct serotypes of AHS virus (AHSV) have been identified by serum neutralization (SN) and molecular-based assays [3]. AHS is endemic in sub-Saharan Africa - from Senegal in the west to Ethiopia and Somalia in the east and extending southward down the African Atlantic seaboard to as far south as South Africa, with sporadic escapades into North Africa, the Middle East, and Mediterranean countries $[1,4]$.

AHS is an endemic disease that is responsible for the death of a high number of horses every year in Namibia. Vaccination is the most effective measure to protect animals, reduce losses associated with the disease, prevent transmission to vectors, and, eventually, allow the eradication of the disease. Liveattenuated vaccines for use in horses, mules, hinnies, and donkeys are currently available. Vaccination with live-attenuated strains of AHSV is the primary means 
of controlling AHS in endemic areas. Concerns have been raised regarding the use of live-attenuated vaccines due to their ability to revert to virulence, their potential for reassortment with field AHSV strains, transmission by vectors, and the difficulty of differentiating between infected and vaccinated animals $[5,6]$. Due to their resistance to the disease, donkeys are considered to be an ideal sentinel species that can be used in the determination of prevalence and distribution of AHSV through the detection of specific antibodies resulting from natural infection [7]. At present, there is no information on the prevalence and distribution of AHSV serotypes in the different administrative as well as foot and mouth disease epidemiological (designated north and south) regions of Namibia.

Therefore, this survey aimed to fill this knowledge gap by investigating the AHSV seroprevalence in Namibian donkeys.

\section{Materials and Methods}

\section{Ethical approval}

The study received ethical clearance from the Animal Research Ethics Committee of the University of Namibia.

\section{Study area}

Namibia is located at $22^{\circ} 58^{\prime} 1.42$ 'S and $18^{\circ} 29^{\prime} 34.80^{\prime}$ 'E in the southwestern part of Africa. It is divided into 14 administrative regions, as shown in Figure-1. A veterinary cordon fence separates Northern Namibia from the southern country parts. Zambezi, Kavango East, Kavango West, Oshikoto, Ohangwena, Oshana, Omusati, and Kunene are the regions located in the northern of Namibia while Erongo, Otjozondjupa, Omaheke, Khomas, Hardap, and Karas are the Southern regions.

\section{Samples collection}

Between October 2018 and July 2019, blood samples were randomly collected from donkeys by professional veterinarians in 13 administrative regions of Namibian. No samples were collected from the Zambezi region because the region does not have donkeys. A total of 260 blood samples ( 20 samples for each region) were collected randomly from unvaccinated donkeys aged between 3 and 5 years that had never been out of these regions. The blood was allowed to stand overnight to facilitate clotting. Serum was separated by centrifugation at $3000 \mathrm{rpm}$ for $5 \mathrm{~min}$, refrigerated, and sent to the Central Veterinary Laboratory in Windhoek for AHSV serological screening.

\section{Serological tests}

All the 260 sera were screened for AHSV antibody and viral serotype screening. AHSV-specific immunoglobulin (Ig) $G$ antibodies were detected

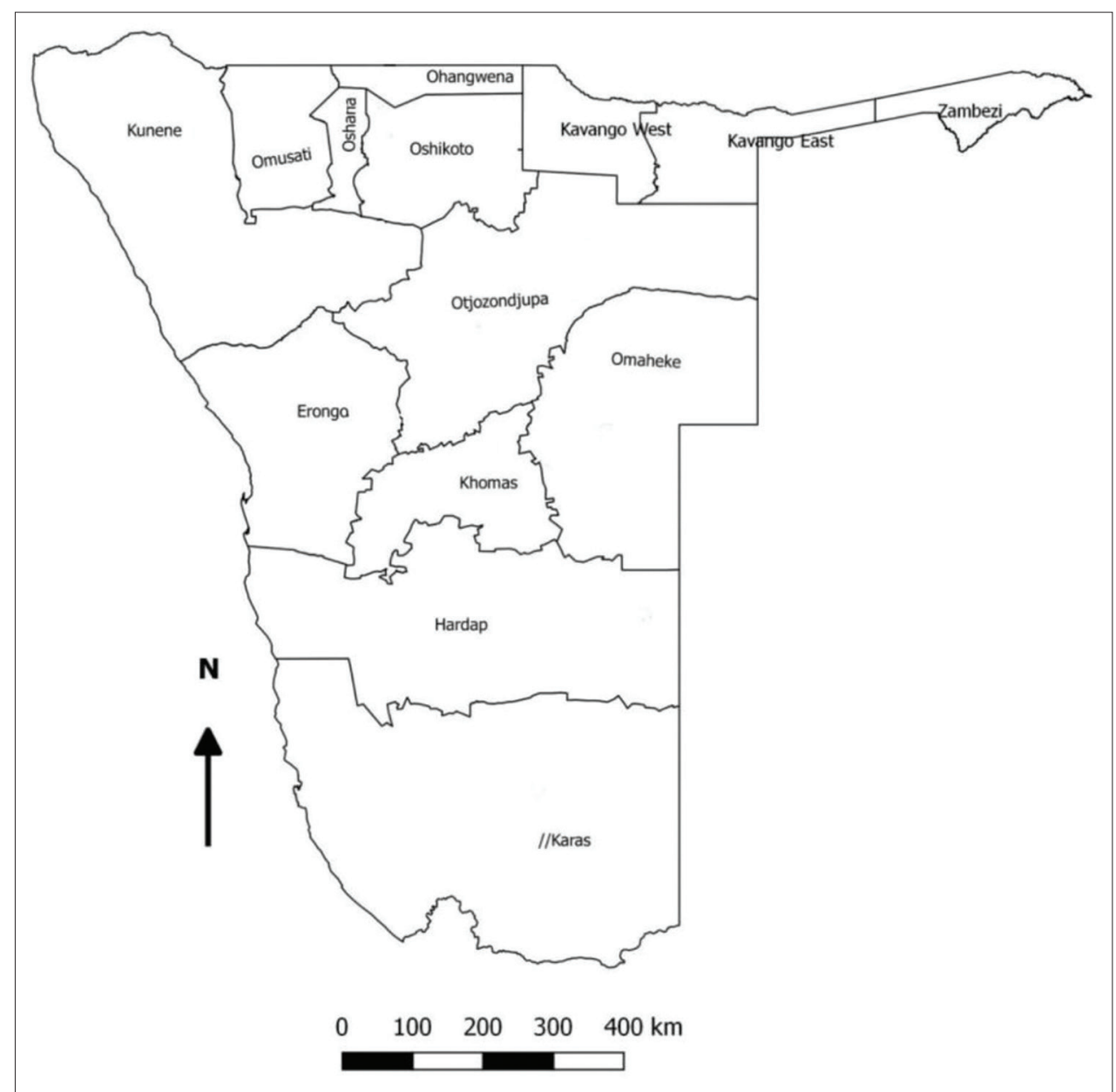

Figure-1: Namibian regions. 
using a commercial competitive enzyme-linked immunosorbent assay (c-ELISA) kit (Ingezim AHSV, Compact Plus, Spain). To evaluate the AHSV serotype-specific immune response, c-ELISA-positive samples were further tested by SN assay. For the SN test, sera were inactivated at $56^{\circ} \mathrm{C}$ for $30 \mathrm{~min}$ before testing. VERO cells provided by the European Collection of Authenticated Cell Cultures (Public Health England, United Kingdom) were used at a concentration of $100,000 \mathrm{cell} / \mathrm{s} / \mathrm{ml}$ for the test. Sera were diluted from $1: 10$ to $1: 1280$ and then incubated for $60 \mathrm{~min}$ with 100 $\mathrm{TCID}_{50}$ of previously titrated AHSV. The virus-serum mixtures were added to 96-well plates with confluent cell monolayers. The specific cytopathic effect (CPE) was evaluated under a light microscope after 5 days of incubation at $37^{\circ} \mathrm{C}$ in $5 \% \mathrm{CO}_{2}$. Neutralizing titer was defined as the reciprocal of the highest dilution of serum able to neutralize at least $75 \%$ of the virus CPE.

\section{Statistical analysis}

Descriptive and inferential statistics were performed using the Statistical Package for the Social Sciences version 25 (IBM Corp., NY, USA). The Chi-square test was used to test differences in the proportional occurrence of AHS in donkeys from the northern and southern regions as well as from the individual administrative regions of Namibia, whereby $\mathrm{p} \leq 0.05$ was considered statistically significant.

\section{Results}

The overall seroprevalence of AHSV-specific IgG antibodies in Namibian donkeys was $63.5 \%$ (Table-1). There was, however, a significant difference in the seroprevalence of AHSV-specific antibodies in donkeys from the different administrative regions $(\mathrm{p}<0.05)$. Donkeys sampled from Kavango East and Kavango West regions had the highest prevalence of anti-AHSV antibodies (100\% and $100 \%$, respectively; $\mathrm{p}<0.05$ ), whereas those from the Karas region had the lowest AHSV-IgG seroprevalence $(40 \%, \mathrm{p}<0.05)$. As shown in Table-2, the AHSV-IgG seroprevalence was significantly higher in donkeys from the northern regions than in those from the southern regions $(64 \%$ and $36 \%$, respectively; $p<0.05)$. There was a significant difference in the distribution of AHSV serotype-specific antibodies in donkeys sampled from the different administrative Namibian regions $(p<0.05)$. Overall, significantly higher proportions of donkeys had antibody against AHSV-6 and AHSV-9 $(37.8 \%$ and $37.8 \%$, respectively; $p<0.05)$. The seroprevalence of AHSV-2 antibodies in donkeys from the northern regions was significantly higher than those from the southern regions $(3.9 \%$ and $0 \%$; respectively, $\mathrm{p}<0.05)$. None of the donkeys in this study, however, tested positive for AHSV-8 serotype-specific antibodies. As shown in Figure-2, the SN assay revealed that the AHSV-IgG-positive donkeys from Kavango East, Kavango West, and Ohangwena regions developed a seroconversion to seven of the nine AHSV
Table-1: Seroprevalence of AHSV-specific IgG in donkeys according to Namibian regions.

\begin{tabular}{lc}
\hline Namibian regions & $\begin{array}{c}\text { Number of donkeys positive by } \\
\text { AHSV c-ELISA (\%) }\end{array}$ \\
\hline $\begin{array}{l}\text { Northern regions } \\
\text { Kavango East }\end{array}$ & $20(100)$ \\
Kavango West & $20(100)$ \\
Oshikoto & $12(60)$ \\
Ohangwena & $12(60)$ \\
Oshana & $12(60)$ \\
Omusati & $14(70)$ \\
Kunene & $12(60)$ \\
Southern regions & $14(70)$ \\
Erongo & $12(60)$ \\
Otjozondjupa & $10(50)$ \\
Omaheke & $10(50)$ \\
Khomas & $9(45)$ \\
Hardap & $8(40)$ \\
Karas & $165(63.5)$ \\
Total & \\
\hline
\end{tabular}

AHSV=African horse sickness virus, IgG=Immunoglobulin $G$, ELISA=Enzyme-linked immunosorbent assay

Table-2: Distribution of AHSV serotypes antibodies in donkeys originated from the northern $(n=7)$ and southern regions $(n=6)$ of Namibia.

\begin{tabular}{lccc}
\hline Serotype & $\begin{array}{c}\text { Northern } \\
\text { regions (\%) }\end{array}$ & $\begin{array}{c}\text { Southern } \\
\text { regions (\%) }\end{array}$ & Overall (\%) \\
\hline AHS 1 & $13(3.0)$ & $8(1.8)$ & $21(4.8)$ \\
AHS 2 & $17(3.9)$ & $0(0.0)$ & $17(3.9)$ \\
AHS 3 & $6(1.4)$ & $0(0.0)$ & $6(1.4)$ \\
AHS 4 & $15(3.4)$ & $14(3.2)$ & $29(6.7)$ \\
AHS 5 & $24(5.5)$ & $8(1.8)$ & $32(7.3)$ \\
AHS 6 & $102(23.4)$ & $63(14.4)$ & $165(37.8)$ \\
AHS 7 & $0(0.0)$ & $1(0.2)$ & $1(0.2)$ \\
AHS 9 & $102(23.4)$ & $63(14.4)$ & $165(37.8)$ \\
Total & $279(64.0)$ & $157(36.0)$ & $436(100.0)$ \\
\hline
\end{tabular}

$\mathrm{AHSV}=$ African horse sickness virus, $\mathrm{AHS}=$ African horse sickness

serotypes (excluding AHSV-7 and AHSV-8), while AHSV-IgG-positive donkeys from Karas and Omusati regions developed a seroconversion only to AHSV-6 and AHSV-9 serotypes.

\section{Discussion}

Annual polyvalent prophylactic immunization against AHSV is practiced in the majority of horses in Namibia [8]. SN assay is not able to distinguish AHSV serotype-specific antibodies derived from immunization, natural infection, or colostrum [7] and a seroepidemiological survey based on the study of the AHSV seroconversion in horses would have been distorted and unreliable. Infection with AHSV is usually asymptomatic in donkeys. As a result, donkeys do not routinely receive prophylactic immunization against AHSV and are, therefore, ideal candidates for epidemiological AHSV serosurveys to determine AHSV field strains circulating in Namibia.

This survey indicated that the majority of Namibian donkeys $(63.5 \%)$ had been exposed to AHSV. The results of the current study are in agreement 


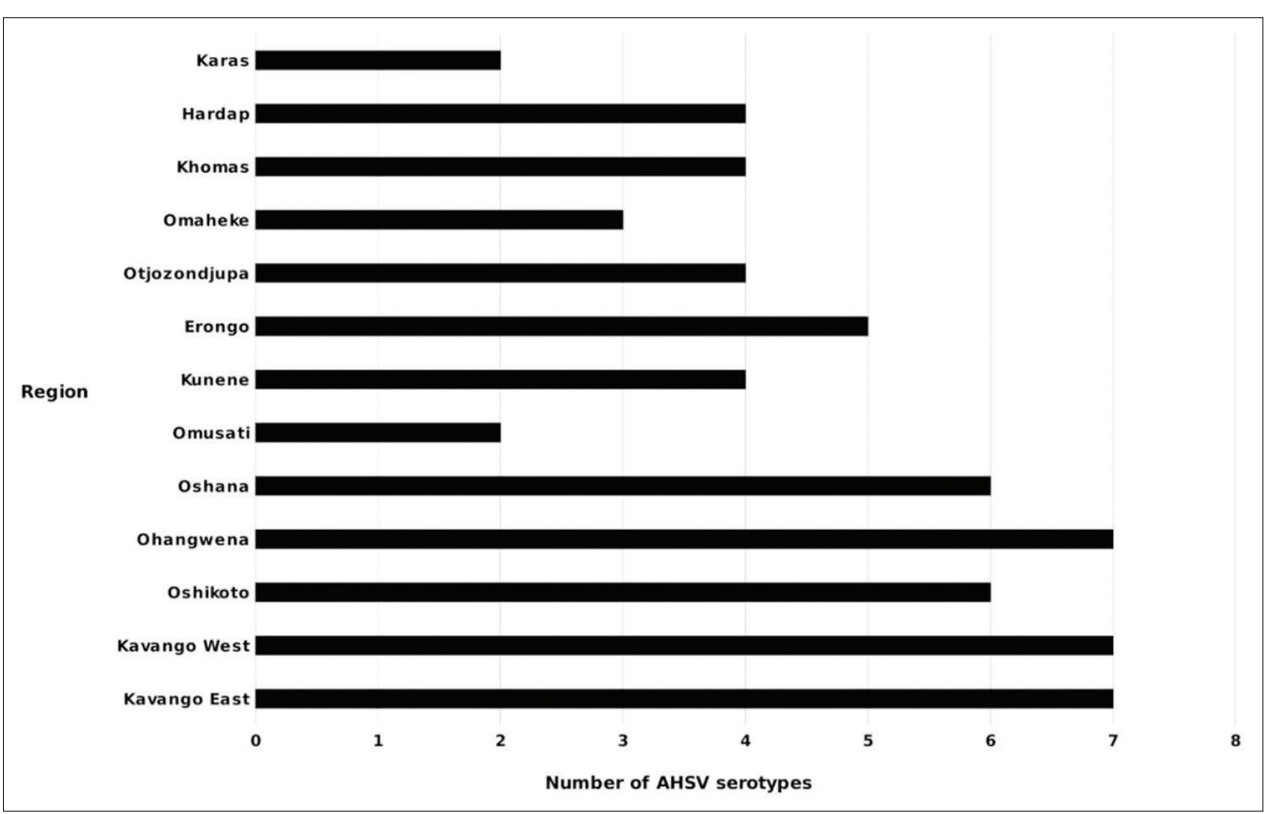

Figure-2: African horse sickness virus serotypes seroconversion found in donkeys by region.

with studies from other African countries that have reported donkey AHSV prevalence of between 59.3\% and $72 \%[9,10]$. It would appear that all AHSV serotypes, except AHSV-8, occur in Namibia. More specifically, AHSV-1, $-2,-3,-4,-5,-6$, and -9 serotypes were identified in donkeys in the wet northern regions of Namibia, while AHSV-1, $-4,-5,-6,-7$, and -9 were detected in the dry semi-desert areas in the southern part of Namibia.

AHSV serotype 9 is not included in the AHS commercial vaccine available in Southern Africa because it is considered to be of low virulence and antigenically closely related to AHSV-6 [11,12]. Moreover, the development of a fully protective vaccine against all nine AHSV serotypes in the horse population may take many vaccination courses over several years $[13,14]$. A recent study demonstrated the circulation of AHSV serotypes 1, 2, 4, 6, 7, 8, and 9 in a few Namibian regions with AHSV-9 being responsible for several AHS outbreaks [8]. AHSV-9 and AHSV-6 were the most prevalent serotypes in the donkeys surveyed in this study.

The isolation of AHSV-8 strain in horses and the absence of seroconversion to the AHSV-8 in all the tested donkeys suggest the possibility of AHSV-8 outbreaks in horses linked to reassortment and reversion of the commercial live-attenuated vaccine as previously described [14,15-17]. SN results showed that several donkeys from Kavango East, Kavango West, and Ohangwena regions might have been exposed to multiple serotypes. Because virus reassortment can occur in nature when a single host or vector cell is coinfected by two or more viruses with segmented genome $[6,18,19]$, the use of multiple attenuated strain vaccines in horses and the detection of multiple strains in donkeys indicate the possibility that cocirculation of several strains occurs in Namibia.

\section{Conclusion}

This study highlighted a high level of exposure of donkeys to AHSV in Namibia with the highest prevalence of seroreactors occurring in the northern regions. Except for AHSV-8, all AHSV serotypes have been circulated or are circulating in Namibia and the predominant AHSV serotypes were AHSV-6 and AHSV-9. Due to the wide spatial distribution of AHSV strains circulating in the field, it is recommended that horses in Namibia be vaccinated as per the recommended protocols to prevent the disease.

\section{Authors' Contributions}

UM designed, coordinated, performed the experiment, and wrote the manuscript. GZ, and SK performed the experiment. EK and GS analyzed the data. $\mathrm{BC}, \mathrm{IB}, \mathrm{CN}$, and $\mathrm{OM}$ collected the samples. BM wrote and edited the manuscript. ND supervised the study. The final manuscript has been read and developed in consultation with all authors. All authors have read and approved the final manuscript.

\section{Acknowledgments}

We express our gratitude to the Istituto Zooprofilattico Sperimentale dell'Abruzzo e del Molise "G. Caporale" Teramo, Italy, for funding the project and for providing positive and negative controls as well as OIE standard reference AHSV serotypes.

\section{Competing Interests}

The authors declare that they have no competing interests.

\section{Publisher's Note}

Veterinary World remains neutral with regard to jurisdictional claims in published map and institutional affiliation. 


\section{References}

1. Zientara, S., Weyer, C.T. and Lecollinet, S. (2015) African horse sickness. Rev. Sci. Tech., 34(2): 315-327.

2. Mellor, P.S. and Hamblin, C. (2004) African horse sickness. Vet. Res., 35(4): 445-466.

3. Sailleau, C., Hamblin, C., Paweska, J.T. and Zientara, S. (2000) Identification and differentiation of nine African horse sickness virus serotypes by RT-PCR amplification of the serotype-specific genome segment 2. J. Gen. Virol., 81(3): 831-837.

4. Maclachlan, N.J. and Guthrie, A.J. (2010) Re-emergence of bluetongue, African horse sickness and other orbivirus diseases. Vet. Res., 41(6): 35.

5. Carpenter, S., Mellor, P.S., Fall, A.G., Garros, C. and Venter, G.J. (2017) African horse sickness virus: History, transmission, and current status. Annu. Rev. Entomol., 31(62): 343-358.

6. Ngoveni, H.G., van Schalkwyk, A. and Koekemoer, J.J.O. (2019) Evidence of intragenic recombination in African horse sickness virus. Viruses, 11(7): 654.

7. Howell, P.G., Groenewald, D., Visage, C.W., Bosman, A.M., Coetzer, J.A. and Guthrie, A.J. (2002) The classification of seven serotypes of equine encephalosis virus and the prevalence of homologous antibody in horses in South Africa. Onderstepoort J. Vet. Res., 69(1): 79-93.

8. Scacchia, M., Molini, U., Marruchella, G., Maseke, A., Bortone, G., Cosseddu, G.M., Monaco, F., Savini, G. and Pini, A. (2015) African horse sickness outbreaks in Namibia from 2006 to 2013: Clinical, pathological and molecular findings. Vet. Ital., 51(2): 123-130.

9. Teshome, M., Addis, M. and Temesgen, W. (2012) Seroprevalence and risk factors of African horse sickness in mules and donkeys in selected sites of West Amhara region, Ethiopia. Afr. J. Microbiol. Res., 6(19): 4146-4151.

10. Gordon, S.J.G., Bolwell, C., Rogers, C.W., Musuka, G., Kelly, P., Guthrie, A., Mellor, P.S. and Hamblin, C. (2017) The seroprevalence and sero-incidence of African horse sickness and equine encephalosis in selected horse and donkey populations in Zimbabwe. Onderstepoort J. Vet. Res.,
84(1): e1-e5.

11. Von Teichman, B.F., Dungu, B. and Smit, T.K. (2010) In vivo cross-protection to African horse sickness Serotypes 5 and 9 after vaccination with Serotypes 8 and 6. Vaccine, 28(39): 6505-6517.

12. Dennis, S.J., Meyers, A.E., Hitzeroth, I.I. and Rybicki, E.P. (2019) African horse sickness: A review of current understanding and vaccine development. Viruses, 11(9): E844.

13. Molini, U., Marruchella, G., Maseke, A., Ronchi, G.F., Di Ventura, M., Salini, R., Scacchia, M. and Pini, A. (2015) Immunization of horses with a polyvalent live-attenuated African horse sickness vaccine: Serological response and disease occurrence under field conditions. Trials Vaccinol., 4(2015): 24-28.

14. Weyer, C.T., Grewar, J.D., Burger, P., Joone, C., Lourens, C., MacLachlan, N.J. and Guthrie, A.J. (2017) Dynamics of African horse sickness virus nucleic acid and antibody in horses following immunization with a commercial polyvalent live attenuated vaccine. Vaccine, 35(18): 2504-2510.

15. Weyer, C.T., Grewar, J.D., Burger, P., Rossouw, E., Lourens, C., Joone, C., le Grange, M., Coetzee, P., Venter, E., Martin, D.P., MacLachlan, N.J. and Guthrie, A.J. (2016) African horse sickness caused by genome reassortment and reversion to virulence of live, attenuated vaccine viruses, South Africa, 2004-2014. Emerg. Infect. Dis., 22(12): 2087-2096.

16. Vermaak, E., Paterson, D.J., Conradie, A. and Theron, J. (2015) Directed genetic modification of African horse sickness virus by reverse genetics. S. Afr. J. Sci., 111(7-8): 1-8.

17. MacLachlan, N.J., Balasuriya, U.B., Davis, N.L., Collier, M., Johnston, R.E., Ferraro, G.L. and Guthrie, A.J. (2007) Experiences with new generation vaccines against equine viral arteritis, West Nile disease and African horse sickness. Vaccine, 25(30): 5577-5582.

18. Domingo, E. (2010) Mechanisms of viral emergence. Vet. Res., 41(6): 38.

19. Chare, E.R., Gould, E.A. and Holmes, E.C. (2003) Phylogenetic analysis reveals a low rate of homologous recombination in negative-sense RNA viruses. J. Gen. Virol., 8(Pt 10): 2691-2703. 